\title{
PRESENT WHILE ABSENT: HOME AND THE BUSINESS TOURIST GAZE
}

\author{
Dr. Cheryl Willis (Bournemouth University) \\ Professor Adele Ladkin (Bournemouth University) \\ Dr. Juliet Jain (UWE) \\ Dr. William Clayton (UWE)
}

To be published in Annals of Tourism Research

\begin{abstract}
This paper reflects on business travel as a contemporary form of mobility and how it relates to family life. Through qualitative research with business travellers, insights are gained into the role digital technology plays in enabling connections to home and family. The paper argues that technology affords a 'business tourist gaze', characterised by a focus on 'home' rather than 'away' as might be the case for leisure tourists. The paper discusses how, through the business tourist gaze, the boundaries between the everyday and the exotic are dissolved and the business traveller is disconnected from the destination, simultaneously absent whilst present both at the destination and at home. Theoretical understandings of the business tourist experience are offered.
\end{abstract}

\section{INTRODUCTION}

Sheller and Urry (2006) proclaimed that 'all the world seems to be on the move' (p207). This appears true in almost all facets of contemporary life as witnessed through unprecedented patterns of travel across the globe, at least for those empowered to move. Embodied in the notion of a new mobilities paradigm, this phenomenon has been studied with increased interest, notably with a focus on how such mobilities shape spatial and social relationships. Despite mobility being at the heart of tourism, in 2005 Hall stated that the concept of mobility had not found much application in tourism studies. However, more recent literature does attest to various lines of enquiry, such as how technology enables the maintenance of social relationships 'on the move' (Molz, 2012), the relationship between different tourist mobilities and sustainable tourism (Lund-Durlacher \& Dimanche, 2013; Moscardo, 2013; Williams, 2013) and importantly for the context of this paper, the distinctions between different forms of mobilities. This points out that travel can be mundane as well as exciting, challenging the binaries of 'everyday' and 'exotic', traditionally offered to describe the differences between everyday life 
and touristic experiences (Binnie et al, 2007; Edensor, 2007; Janta et al, 2014). This is important when considering business travel where experiences may differ markedly from those of the leisure traveller. The mobilities paradigm thus lends an important perspective to investigating how business travel is experienced and how it 'resonates with people's lives, their identities, their ways of knowing and being in the world' (Coles, 2015, p63).

Central to these discussions is the role played by digital technology in facilitating business travel and enabling work on the move, and in negotiating and maintaining social relationships where co-presence is not possible. Despite the proliferation of technologies which in could reduce the amount of business travel required, a 'compulsion to proximity' (Boden \& Molotch, 1994) means that face to face meetings are still often preferred for the trust and deeper relationships they engender between contacts (Bergstrom, 2010; Jones, 2013). As networks are increasingly stretched across space, so business travel continues to keep apace. The role of technology for enabling work on the move is well understood, whilst the use of technology for connecting to home for the business traveller remains limited. This area of enquiry is important as it has been evidenced that business travel can be demanding physically and psychologically (Espino et al, 2002) and connecting home and being 'virtually present' may help to alleviate some of these negative consequences of business mobility.

Connecting to home is not the sole preserve of the business traveller, as leisure travellers also engage in a range of practices surrounding keeping in touch with home (Gretzel \& Jamal, 2009; Molz, 2012). However, there may be a distinction in terms of priority. The concept of the 'tourist gaze' (Urry, 1990, 2002; Urry \& Larsen, 2011) is useful in investigating some of these distinctions between experiences of business travellers and those travelling for leisure purposes. The tourist gaze is founded on the premise that tourists gaze upon what constitutes difference from their everyday lives. It asserts that tourists 'consume goods and services because they generate pleasurable experiences which are different to those typically encountered in everyday life' (Urry, 2002: 1). This paper asserts that business travel challenges this notion as although it may contain elements of 'difference' and 'pleasure', experiences differ in important ways, particularly for the frequent business traveller whose travel is constant or occurs in close succession. Evidence from qualitative research with UK employees who travel for business is discussed in this paper. This points to a certain disconnect from the travel destination, a desire to connect to home and to be virtually present to take part in the 'mundane' rituals of everyday life via technologies available to them, rather than seeking out and embracing difference and 'the exotic'. For the business traveller, modern technologies may also foster an obligation for connection and availability, which means they are afforded little of the time for relaxation and escape traditionally associated with tourism. This paper argues 
therefore, that frequent business travellers obtain different perceptions of touristic spaces and develop a different 'gaze' to their leisure tourist counterparts despite inhabiting the same space at the same time; an understanding encapsulated in the idea of the 'business tourist gaze'.

This paper explores how the business tourist gaze is constructed and reinforced by technology which is used to reconfigure presence and absence for the business traveller at home and at the destination area. Through the voices of contemporary business travellers, it makes an important contribution to a more nuanced conceptualisation of business travel as a hybrid practice where travel and tourism are mixed with more mundane practices of work and thoughts which are more reflective of home and the 'everyday'. The paper considers possibilities for future research focused on this uneasy relationship between business travel and tourism and the role of technology in negotiating social relationships for different kinds of travellers. The following section provides the context for investigations into how business travel, as a core part of contemporary mobility shapes these relationships and the role of technology in this process.

\section{MOBILITIES, BUISINESS TRAVEL AND TECHNOLOGY}

Business travel is recognised as important to the economy. In the UK for example, there were approximately 8 million business visitors in 2014, contributing $£ 5$ billion to the economy (UK ONS, 2015). Globally, some 14\% of international tourists reported travelling for business purposes (UNWTO, 2015). As well as financial benefits, business travel enables a host of other benefits such as the spread of knowledge and professional practices and the building of better understanding and relationships between different regions and cultures (UNWTO, 2014). However, research on business travel is relatively limited within the tourism literature, although in the wider research arena, interests include categorisations and typologies of business mobility (Jones, 2013; Aguilera \& Proulhac, 2015), travel time usage and commuting (Lyons, Jain and Holley, 2007; Hislop. 2013), business travel practices (Beaverstock \& Budd, 2013; Hislop \& Axtell, 2015) and business travellers' health and well-being (Bergstrom, 2010, Espino et al., 2002; Gustafson, 2012, 2014). Research has also focussed on the complex debates around the seeming paradox of increasing mobility despite the proliferation of new technologies which, in theory, could limit the need for such mobilities.

The reasons behind this paradox are complex. Changing working practices such as outsourcing, international project teams and multi-unit companies create opportunities for travel (Gustafson, 2012). In addition, despite opportunities for a virtual presence, evidence suggests a continued need for co-presence (Falconbridge \& Beaverstock, 2008; Aguilera, 2008; Gustafson, 2012). For organisations to function, face-to-face contact seems to be required to facilitate the development of personal relations and building trust (Bergstrom, 2010, Falconbridge \& 
Beaverstock, 2008). What appears to be happening in practice is a combination and interdependence of co-presence and virtual presence (Haynes, 2010; Räsänen et al.,2010). A deeper exploration into the reasons why co-presence remains important is offered by Strenger (2015) who builds on Urry's concept of corporeal travel, emphasising the role of the embodied nature of meetings and how the proximity of bodies to other bodies and places is "obligatory, appropriate or desirable" in the practice of business meetings (Strenger, 2015: 596).

In recent years, the study of mobilities, or the movement of people, objects, capital and information has become a subject of intense research largely in recognition of the processes of globalisation which has seen social and business networks expanding across the globe with the need for communications, both virtual and corporeal, responding to these changing conditions. Within these processes, complex spatial and social relationships are formed and understanding these and how they are shaped by the process of travel has emerged as an area of research interest within the mobilities paradigm (Moltz, 2012; Sheller \& Urry, 2006). The 'mobilities paradigm' considers social relations within discussions of travel and acknowledges the complex social relationships which emerge as a result of contemporary mobility. Tourism, as a form of temporary mobility, is central to these discussions and is best understood in a more holistic way, recognising how as a practice it is embedded in a system described by Bauman (2000) as 'liquid modernity'. Mobilities thus has important implications for those moving, the places where movement occurs and the industries which support these mobilities. The mobilities paradigm invites us to look more closely at these movements and the relationships they create and to examine them in a more integrated way. This includes all forms of mobility as even those considered banal or mundane can be noteworthy, despite the assertion that 'commonplace journeys are all too easily neglected amidst academic scrutiny' (Binnie et al., 2007: 166). For the business traveller, mobilities may become 'normalised' (Gustafson, 2014) and thus more banal than exciting, anticipated with a sense of 'reliable expectation rather than eager anticipation' (Binnie et al, 2007: 169). However, it is important to recognise that mobilities are not evenly distributed across societies and not everyone is part of the mobile world (Cresswell, 2010). Bauman's (2000) "liquid modernity" is largely formed of hypermobile elites who frequently change places of work, social networks and places of residence. These hyper elites are assigned high status, as mobility in relationships, work and leisure increasingly defines a person's standing in society (Urry, 2012). At the other end of the spectrum are those who are less mobile. Adey (2006) sorts these mobile bodies into kinetic elites and kinetic underclasses. In the context of airports, passengers are subject to power and control, and divided into fast and slow moving streams. The kinetic elite are embodied and move through quickly, and the kinetic underclass are unknown, disembodied and move more slowly. Cresswell (2012) provides a detailed overview of the complexities, status and recent debates. 
Understanding the nuance of business travel is a somewhat difficult undertaking, as even defining the practice is complex. Swarbrook and Horner (2001) for example, divide the topic of 'business tourism' into at least fifteen different categories of travel, including individual general business trips, training courses, product launches, and corporate hospitality and incentive travel. Moreover, some business travel will also incorporate a leisure component which means that in some ways, business travel and leisure travel intersect and may share similar experiences, thus a complex picture of business mobilities emerges (Tretyakevich \& Maggi, 2012). For the business traveller, experiences may be both stressful and stimulating. They may be associated with career enhancing prospects and interesting and rewarding experiences but equally may be associated with physical and psychological strain which can manifest in stress, burn-out, feelings of guilt for family at home and physical and mental fatigue (Gustafson, 2014; Black \& Jamieson, 2007; Ivancevich et al., 2003; Westman \& Etzion, 2002). Recent work by Cohen and Gössling (2015) offers an examination of the 'darker side' of excessive mobility, reviewing the glamorisation of mobility and discussing the psychological, emotional and social costs for both societies and individuals. A lack of co-presence with family and friends and a weakening of ties in the local community are identified as a cause of isolation. These social consequences are also observed by Bergström (2010). In Gustafson's (2014) study, the most stressful consequences for business travel were found to be related to balancing work and private life. Frequent travel was often associated with feelings of guilt for not undertaking a 'fair share' of domestic work and also feelings of loneliness and separation, not only for the traveller but also for other family members. This leads to recognising that the consequences of business travel are gendered. At one level, within the business travel sector there is an over representation of men (Aguilera 2008). One reason for this is that the responsibilities of running a home make it more difficult for a woman to accept a job where frequent travel is required (Collins \& Tisdell, 2002; Gustafson, 2006). As women appear to be more involved in the caring and maintenance duties associated with family life, it has impacted on their mobility opportunities and choices, which may affect the types of employment they are able to engage with (whether through choice or discrimination) (Casinowsky 2013; Black \& Jamieson, 2007). Even when women are the main travellers in the family unit, they may still undertake the majority of domestic responsibilities (Casinowsky 2013). The gendered nature of business travel adds to the complexity of this type of mobility and how social relationships are maintained.

Perspectives on business travel highlight that particularly when travel is frequent, it has significant impacts and can put undue stress on the traveller, on those left at home and lead to 'a progressive disconnect from family and friends' (Black \& Jamieson, 2007: 64). Technology has an important role in shaping these experiences and for business travel, as there appears to 
be a continual wrestling of competing priorities for virtual travel and a compulsion for proximity. Larsen et al (2006) discuss this in light of the inadequacy of technology to fully replicate copresence and a continued need for co-presence where face-to-face meetings and the 'social cues provided by embodied encounters' (Faulconbridge et al., 2009: 296) appear to be especially important in professional situations where they engender a sense of trust and respect. For connecting the business traveller and ensuring that work can be done on the move, technologies have proved invaluable, although the resultant situation of 'constant contact' and 'round-the-clock emails' (Black \& Jamieson, 2007: 64) has opened up the debate regarding the consequences of blurring of boundaries between work and social life which some argue 'encourages work problems to colonise the social spaces and times once reserved for family life' (Wajcman et al., 2008: 636).

However, for connecting to home and for strengthening social relationships over geographical distance, technology has considerable merit. Greene et al., (2010) for example, argue that rather than fragmenting relationships, time spent using communication devices can make relationships more durable. Technology shapes the experiences of the traveller and for some provides a sense of comfort and constant connectedness (notwithstanding practical connection issues) with social networks despite geographical distance (Moltz, 2012). Technology thus enables people to be both present and distant at the same time which may serve as a valuable link to family life or conversely, as a reminder of geographic distance. By enabling the business traveller to be physically mobile while emotionally and mentally 'at home' (White \& White, 2007), technologies enable a different focus than may be apparent for the leisure tourist who may delight in being 'away' and geographically distant from 'home' and its connotations of the everyday. The following section explores further how the focus and experience of the business traveller differs in important ways from that of the leisure traveller and how technology plays a role in constructing the 'business tourist gaze'.

\section{THE RISE OF THE BUSINESS TOURIST GAZE}

The mobiltiies paradigm reminds us that different forms of mobility shape and organise social life in various ways. Tourism is very much part of this picture and researchers have begun to view tourism as increasingly constitutive of everyday life, rather than being simply an escape from it (Hannam, 2008; Coles \& Hall, 2006; Edensor, 2007; Hannam et al., 2014). Coles et al (2005) argue that the consequences of 'shoe-horning tourism into the narrow slipper of the extraordinary and the exotic has been to divide tourism from other forms of mobility' ( $p 36$ ). Tourism is as much about the movement of people, technology and information as any other form of mobility. However, this understanding, although important, does not totally unravel the distinctions in the experiences of different tourists who travel for different reasons and who 
experience the process of travel and the destinations they visit differently. Urry's conceptualisation of the 'tourist gaze' $(1990,2002,2011)$ is valuable in understanding some of these experiences.

In early iterations of the 'gaze', Urry $(1990,2002)$ argues that tourists gaze upon what is considered different from everyday life which thus brings a sense of escape and pleasure. Furthermore, he posits that 'when we 'go away', we look at the environment with interest and curiosity' and that the very notion of going away is constitutive of a 'breaking of routine and practices of everyday life' (Urry, 2002: p1-2). This may not be the case for the business traveller who, despite being corporeally present in settings which might otherwise be considered 'exotic', are bound by work duties and thus continue to be embroiled in the mundane and the everyday. Moreover, as Kesselring and Vogl (2010) argue, business travel is currently undergoing a process of 'normalisation' and 'rationalisation' which tends to eliminate the stimulating and rewarding aspects of travel. Previously, business travel was often regarded as a privilege and an indication that the traveller was an important and trusted employee. Today, as more and more employees are expected to travel, it has become for some, a banal, routine activity, and employers' demands for mobility are often perceived more as a burden, a 'business travel curse' (Beaverstock et al, 2009: 196) rather than a reward.

The tourist gaze was originally constructed upon an understanding of the visual as the dominant mode of consuming scenes and that these scenes were enjoyed by tourists by virtue of their difference to their everyday realities. The gaze then may be somewhat different for the business traveller who finds him/herself enmeshed in a world associated with signs and practices usually indicative of non-work practices such as spaces designed for leisure and pleasure whilst his/her focus remains on work obligations. She/he may therefore, be caught in a dichotomy of colliding worlds where the gaze may be one of interest and curiosity but, in contrast to leisure tourist counterparts, it may also be tinged with melancholy and sadness at not being able to engage fully in the 'scene' and not being with those who would normally enjoy such scenes as part of a family unit. Urry suggests that the gaze is entirely socially constructed and it is argued here that how the gaze is organised and remembered, appears to depend on frame of mind and the company in which it is encountered. Moreover, since the business tourist gaze is highly organised and directed often to scenes of familiarity associated with the corporate world rather than highlighting difference in a destination, it will not necessarily induce feelings of difference and pleasure for the business traveller.

Such feelings may not be entirely unique to the business traveller as increasingly it is recognised that travel, tourism and everyday life intersect in complex ways (Larsen, 2008). 
However, the inclination of the business traveller to focus on the everyday and what is missing from the destination rather than embracing what is different in the destination, may lead to a desire to seek 'absence' from the destination, in favour of 'presence' in the familiar and routine of 'home'. For this group, they may re-configure the tourist gaze through technologies which enable this absence and presence, leading to a gaze in which the familiar and the everyday are contrasted favourably to the exotic and the extraordinary. However, this can be contested, as some business travellers may enjoy the escape from routine and the complexities of family life. This notion of business travel as a 'respite' from the normal workplace, home and family is articulated by Westman, Etzion and Chen (2009).

The tourist gaze has received criticism for its focus on the visual as the dominant mode by which tourists experience destinations, at the expense of other bodily ways in which tourists might come to know destinations. Inspired by the 'performance turn' which privileges practices and the multi-sensuous ways that tourists experience places, commentators suggested that the gaze can equally be constructed through various senses. Franklin \& Crang (2001) for example, argue that 'flavours, touches, smells and sounds and doings, as much as vision and visual objects, can produce difference and the sense of the 'extraordinary' ( $p 14)$. The third edition of the Tourist Gaze (Urry \& Larsen, 2011) thus re-thinks the tourist gaze to include performance and embodied practice as equally important in the tourist experience, although they maintain that performances are important in part because they take place within distinct visual environments. For the business traveller, it is argued that embodied and sensuous experiences may not hold the same sense of appeal as they might in other leisure situations. This may be due to work demands having to take priority, resulting in what Molz (2012) terms 'ambiguities of presence' $(p 10)$ in the host environment. The business traveller will of course be corporally present during the business trip and will no doubt experience the destination through the senses, however, the experience of 'difference' is what sets them apart from the leisure traveller. Notwithstanding that some business travellers do delight in such experiences and embrace time away from the routine of home, it is argued that particularly for frequent business travellers, their gaze, which might during non-work occasions, be shaped and stimulated by difference and sensuousness, is at least partly marred for some by thoughts of missing home and anxiousness about a loss of role and shared discourse within the family unit (Black \& Jamieson, 2007). This can result in a sense of detachment from home and so, whilst business trips may be 'an attractive break from routine', (Westman \& Etzion, 2002: 589), they can also involve feelings of anxiety and guilt and less desire to embrace the opportunities and difference of the 'new' environment, 
Whilst both 'performance' and 'gaze' are thus important in the tourist experience, for business travellers, they may not 'dance together' (Larsen and Urry, 2011: 1122) in quite the same way as for leisure tourists, in that they may not be quite so mutually satisfying. For leisure tourists who may be persuaded to visit and re-visit destinations through 'embodied empathy with a destination' (Hannam, 2008: 131), the business traveller may not hold the same embodied empathy and experiences of destinations may be much more functional. For this group, experiences which may be pressured and resisted, contrast sharply to those who 'anticipate and daydream about new or different experiences from those normally encountered in everyday life' (Urry, 2002: 14). In interesting ways then, the binaries set up in tourism which contrast the exotic and the everyday are challenged through business travel and distinctions are increasingly blurred. Business travel thus provides an important opportunity to examine these ideas in greater detail and to understand more fully the processes and impacts of business mobility on social relationships and how the gaze, argued to be embodied and sensuous as well as visual, appears to be constructed by the business traveller in ways which are distinct from 'holiday' experiences. This is a rich concept which deserves further research attention. The following sections seek to explore these ideas by drawing on empirical research with contemporary UK based business travellers.

\section{STUDY METHODOLOGY}

This paper draws on research conducted through a two year multi-disciplinary study funded by the Engineering and Physical Sciences Research Council (EPSRC) exploring the evolving nature of family life within the digital age to support work-life balance for those who travel for work. The aim of this study was to understand the domestic rituals that families share, and how existing technologies are used by people travelling away from home in the course of work to connect with 'home life', and how they enable participation in it. The research took a multidisciplinary perspective on these issues, combining extant qualitative social science approaches with design-oriented research in an overall creative orientation to qualitative research. The first stage of the research comprised of interviews with organisations that have a partially mobile workforce. Stage two comprised of interviews with mobile employees and their families. The final stage undertook in-depth design led ethnologies with five families, resulting in the deployment of technological prototypes designed to connect absent workers with home. Data triangulation was thus achieved for the wider objectives of the study. 
In this paper, the empirical evidence is drawn from stage two which explored, via qualitative interviews with business travellers, experiences of business travel and of being away from home and how digital technologies enabled a sense of presence at home whilst absent for work purposes. Participants were recruited via employers who had taken part in the first stage of the research and also through advertisements placed on social network sites such as Linked-in and Mumsnet, press releases, and word-of-mouth contacts. When replies were received from these different calls for participants, the researchers arranged the face-to-face interview that for the most part took place in the respondents' homes. For the purposes of this research, participants were included if they travelled away from home overnight as part of their job with a frequency of six or more trips per year, or fewer but with a significant duration. This was deliberately broad as we were not targeting those with a particular travel frequency. The recruitment strategy employed was designed to enable a variety of workers who are mobile and travel in the course of work to participate, not simply those classified as 'professional workers'. This was intended to give as wide a perspective as possible on the particular experiences and challenges faced by such workers. Participants however, mainly fell within a 'professional' category and represented professions such as lawyers, consultants, journalists and project managers. A high proportion of participants had some level of autonomy over their mobile working patterns. Whilst this was not true for all participants, this means that the experiences of the mobile workers in this study must be understood in the context of their autonomy. In total, twenty-two interviews were conducted. Details of the characteristics of the sample are given in table 1.

Insert table 1 about here

Interviews were semi-structured and focussed on work roles, the frequency and rational for work-related travel, what they enjoyed and disliked about travelling, before exploring family life, including family activities that held significant meanings for them. The ways in which family shaped the experience of absence was also explored and how digital technology was used for communicating with family members and issues around work-life balance. For the purposes of this research, the definition of 'family' was broad and the only stipulation given was that the participant must be living with at least one other person (e.g. partner, spouse, child, parent, etc.), and the invitation to participate stated that a family could be a diverse set of combinations of people. Our intention was not to target those with a particular domestic arrangement or age group of children. The interviews were flexible enough to allow the participant to elaborate on any particular questions or aspects they wished to, with the researcher guiding them through the different aspects of the question schedule. 
Interviews took place in the participants' home and they lasted for approximately ninety minutes. Interviews were recorded, transcribed and analysed thematically (Strauss \& Corbin, 1998) using NVivo (10) software. Thematic analysis is a widely used analytical method, and has been argued to be one of the few shared generic skills across qualitative analysis (Holloway \& Todres, 2003). Guided by Braun and Clark (2006) themes capturing something important in the data were explored in relation to the research questions. Nodes were created initially based around the themes identified as important in relation to our lines of enquiry given above and which formed the structure of the interviews. Subsequent nodes emerged from the data and were examined in the context of wider themes; 'technology and communication' for example, revealed a number of rich and varied sub-nodes including 'limitations', 'functions', 'frequency' and 'reassurances'. Quotes are used to emphasise certain points. The two researchers who conducted the interviews also carried out the thematic analysis. As such they were immersed in the data and worked alongside each other, communicating and reflecting together as part of a continuous process to foster inter-coder reliability.

The following section is designed to offer insights from contemporary UK based business travellers into this practice and the impacts it has on family life and how technology is used to mediate the travellers' relationships to home. Empirical evidence is presented relating to four areas; what business travellers miss about home whilst travelling; the impacts business travel has on family relationships; how technology is used to create a sense of presence at home and how business travel is conceptualised as a hybrid practice which blurs the boundaries between tourism and the 'exotic' and practices of the mundane and everyday. Whilst some of these findings are familiar to the business travel literature, and to an extent to the tourism literature, this study provides new empirical evidence to enable further analysis of how complex social relationships are negotiated across time and space and how business travel has ushered in a reconfiguration of the tourist gaze.

\section{STUDY FINDINGS}

\subsection{Missing family rituals}

Participants spoke about the rituals of family life, the kinds of everyday practices which had meaning for them and which they missed whilst they were travelling. For some, this was about significant events which they have missed such as children's birthdays whilst for others it was more about the normal, routine things which they were unable to take part in whilst travelling. The following quotes illustrate some of these everyday routines which reflect the meaning they have for the business traveller: 
'Just being around, you know, to iron the school uniform and get those daily rituals that all, you know, parents of school age children have to do, I miss doing that. It just makes me feel sad'. (No.18, female, lawyer)

'We always eat together in the evenings you know? Sit down at the table and eat together. When I'm away, we obviously don't do that' (No.5, female, consultant)

For some, the feelings of separation and loneliness were about not having someone familiar to talk to and in particular, not having tactile contact with other people 'being in bed with somebody is what I miss' (No.1, male, consultant). This was something quite important to many respondents as travelling with colleagues was noted as a very different experience from travelling with family. For many respondents, the experience of 'being away' was tinged with a longing for the normal routines of home; 'I miss my house and sort of just being at home' (No.6, male, consultant). Even where the surroundings were extraordinary, some still craved the comforts and the familiarity of 'home':

'I know that people think I'm ungrateful, being able to stay in some of the most stunning hotels that I couldn't afford to pay for myself, but there is nothing like being amongst your own belongings and in your own bed' (No.21, male, flight crew).

\subsection{Impacts on family/social relationships}

For some, the impact on family life was seen in a positive light in terms of having a unique perspective on the importance of being together, highlighted through absences which manifested in more intensified periods spent together; "we sort of make more of an effort to go out and do things as a family over the weekend' (No.3, male, consultant).

For many respondents, feelings of isolation and helplessness whilst travelling were paramount in recollections, not only when recalling family rituals they miss but also in times when they felt unable to help such as when children or partners are ill such as the following quote illustrates:

'When he's poorly, it's sad to see because you like to think that you're a reassurance to your children. You kind of like to think that your presence is reassuring and comforting and I can't do that when I'm away (No.6, male, consultant)

For children, periods of absence may be especially hard and one respondent noted that whilst he remembered many of the times when he was present and able to read bedtime stories to his son, what his son remembered were the times when he couldn't; 'they, you know, throw it in 
your face, 'I've sat on the stairs waiting for you to read to me and you're not there" (No.11, male, journalist).

Feelings of both guilt and appreciation for partners and other family members who have to work harder to maintain family rituals and the rhythms of daily life, were also apparent in discussions with business travellers; 'she works extremely hard when I'm not there, ferrying the kids around so I do feel guilty' (No.17, mail, oil industry). These feelings may be exacerbated and misunderstood as feelings of resentments sometimes build up regarding the absent partner who may be thought to be enjoying themselves, relaxing and being 'on holiday' whilst family life goes on, such as illustrated in the following quotes:

'For some reason, she gets the idea that because I'm working away, that I'm having a great time, she just thinks I'm on a jolly, on holiday for two weeks' (No.22, male, oil industry)

'I think she resents it sometimes the fact that I could be off, you know, going for a nice meal, relaxed company while she's dealing with all the drama of the family and the kids and stuff so I try to avoid that level of conversation with her' (No.17, male, oil industry).

'She's obviously acting as a single parent when I'm away so that's hard from her side' (No.1, male, consultant)

\subsection{Technology for creating a sense of presence}

Feelings of being isolated and excluded from family life were raised as important for some business travellers; 'a difficult part of being away is that they get to carry on with normal life and you are somewhat excluded being away' (No.9, male, pilot). For many, the use of technology was primarily about trying to maintain this contact, this sense that they still had a role to play in family life and that they could be part of it. This may be about trying to maintain some kind of presence or 'normality' in family life whilst away, or about ensuring that family memories are preserved and shared as reminders of the one who is absent and their central part in the family as the following quote illustrates:

'I started like valuing more having a family day out, at a national trust place or whatever. I find that I take some photos while we are out and then you know when I'm away or on the train or whatever I'll actually upload them to Facebook while I'm away and that's a nice reminder of what we've done. I feel it like it shows that I care' (No.3, male, consultant) 
New technologies which enable more expressive communications were often used as a way to intensify the feelings of being closer to family members whilst away and they also enable family members to virtually travel with them, to be part of the experience of being away such as in the following quotes:

'I always show him my hotel room which somehow, it helps me as well, you know? Here's the bed and here's the bathroom and it just feels like, for me, it feels like l'm not alone' (No.5, female, consultant)

'They take the ipad around the house and show me things they've made or drawn or pictures or something. I'll show them where I am and what the view is like' (No.9, male, pilot)

Technologies which enable even a snapshot of a moment were also important for updates on family life and to keep connected whilst absent. Snapchat for example, was mentioned as a useful application to capture moments which are meaningful such as in the following;

'My wife snapchats me a little cool thing of our son smiling or snoring or when he's giggling in his sleep which is nice, it's just like a snippet, it makes me go 'oh I want to be there', just like a little kind of snapshot of my life, my normal life at home' (No.6, male, consultant).

For some participants, technology was most useful for 'checking-in' or functional contact via telephone, email and text. This may be for reassurance that all was well and also for very practical reasons of being able to continue to perform family duties such as paying the credit card bill and organising family arrangements; 'updating our shared calendar on Gmail' (No.10, male, technical adviser) for example. The limited capacity for technology to fully replicate physical contact and the feelings of 'being home' were however, also noted:

'It is not the same sort of quality time and sometimes the children are not themselves on skype' (No.3, male, consultant)

'Having those conversations, it doesn't replace sitting down and having a meal and having a good chat' (No.7, male, NGO worker)

In some instances, such virtual contact appeared to worsen the situation by contacting family at times which may not fit in well with family plans, perhaps because of the difficulties of timezones and also because such contact reminds family members of the geographical distance between them; 
'I personally wonder whether actually seeing them makes it feel worse. You know, we speak on the phone, it's obviously different in you don't see them, but I think that some technologies can make you feel worse' (No.3, male, consultant)

'You kind of have to try and think when it is a good time to call for them as they are getting ready for school. So it's not always well received. It's distracting' (No.9, male, pilot)

For others, technologies which enable virtual presence, do provide a sense of 'being present' and appeared to be a source of comfort. By being able to see someone, many participants felt that they had shared some quality time with loved ones, rather than simply passing on information about each other's well-being. The following quote are good examples of this:

'My little boy will kiss the screen and you know, that is fascinating. A lovely thing to do because he actually, he sees that as being together' (No.12, female, consultant)

'Facetime has become very important to us. I guess it's something that happens in our brain when you see someone as well as when you hear their voice and it feels like you've spent some time with them rather than you've just had a conversation. It feels more intimate' (No.5, female, consultant)

\subsection{Blurring the boundaries between the exotic and the everyday}

For many participants, business travel sets up complex relationships with family, with the destination visited and also within oneself. Largely, this stems from an uneasy relationship of business travel as a touristic activity and with business travellers inhabiting the same space as other tourists and yet not really experiencing the same things in the same way. For the participants in this study, travel experiences and destinations varied. Typically, they were considered as 'exotic' by virtue of being overseas. However, even for those who travelled across the UK, the extraordinary experiences of staying in 'luxurious' hotels and having meals provided for example, added a sense of the 'exotic', particularly for family members reflecting on the trip of a loved one, even where location did not necessarily support this assumption. Despite these hallmarks of a 'holiday', dichotomies are evident in how the situation is perceived and experienced. For leisure tourists, such situations would be a time to relax and to forget about work and daily pressures, whilst for the business traveller, work is the central reason for being in the destination and work pressures form part of the ritual of daily life, despite the setting. Business travel is also tiring for many, especially if travel for work becomes more frequent and 
routine; 'it's actually really tiring going up and down the country you know' (No.1, male, consultant).

For some, the experience of travelling was exciting, and recollections of experiences were as animated as for any holiday, with benefits including "I get taken to some places that I would never have gone to on my own' (No.10, male, technical adviser) and 'I meet lots of different people which I really enjoy and its extremely intellectually challenging' (No.5, female, consultant) and 'you open the doors, it's a different climate, people speak a different language, different currency and I always find that exciting' (No.9, male, pilot). For others, business travel was not so much an exciting and stimulating experience, but one characterised by loneliness and a sense of having to be 'on show' and not being about to engage in 'normal' practices as the following quotes demonstrate:

'Sometimes, you've got to go through the motions of getting somewhere and then you've got to go out for a meal and you've got to do this and you've got to do that, so that's a bit tedious' (No.17, male, oil industry).

'I miss having the ability to go and get breakfast without having to get washed and dressed before going down to the hotel. You are constantly on show when you are travelling so you are constantly being, there's no normality to it, everyone is a customer. So you are acting all the time, it's a week-long show of smiles' (No.10, male, technical adviser).

A certain sense of disconnect from the destination was also evident from interviews as, whilst, as shown, some participants are stimulated by the experience of business travel and endeavour to make the most of opportunities presented, others are less inclined to engage with the destination and view the experience as one to be endured and with a sense of obligation to focus on work. This was not only about being productive in a professional sense, although that was clearly important, but significantly, a focus on work whilst away appeared in many cases to be motivated by a focus on home; an opportunity to free up time to re-integrate and to participate fully in family life on their return.

'My compromise is when I'm abroad I work as many hours, twelve hour day, thirteen hours, fourteen hours, whatever it takes so I don't have to when I am home' (No.14, male, sales director)

'I use time on my own in a destination for boring things, I save them up so I don't have to do them when I get home' (No.9, male, pilot) 
In contrast to traditional perceptions of holidays and trips abroad where experiences might typically be about spending money and experiencing all a destination has to offer, time away on business travel was discussed sometimes in a very different light;

'I work in the evenings because I haven't got anything better to do basically. I work much longer hours you know when l'm away' (No.3, male consultant).

'You generally save a bit more money when you're not at home because you are sort of isolated, going to work, coming home, sleeping, getting into that routine so you are not out in the evenings much' (No.22, male, oil worker)

For many of these participants, experiences of being away were at least, for some of the time, tinged with negative emotions such as guilt, loneliness and sadness. Despite being physically present in what might be described as 'exotic' locations, for some, their focus was firmly on home and craving the familiar.

'I miss coming in from work and just being able to sit on the sofa and talk to someone else. When I come into a hotel room, I have just got a bed, no sofa and it doesn't feel like a lounging area' (No.22, male, oil industry)

'Sometimes, you know, you just want familiarity. I love eating out and I love great food but sometimes, you don't want all of that choice. Sometimes you just want to be in your own house and your own bed' (No.5, female, consultant)

\section{DISCUSSION}

This research provides insights into business travel as a form of contemporary mobility, the mobilities paradigm being useful for framing these insights and for highlighting the complex social and family relationships which result from business travel. It has drawn on some earlier discussions around the differences between experiences of business travellers and leisure tourists and argues for a re-configuration of the tourist gaze based around the premise that business travellers may prefer to gaze upon and to be immersed within familiarity rather than embracing 'strangeness' in contrast to leisure tourists. These distinctions are not however, without difficulty. For example, commentators have illustrated in recent years how strangeness and familiarity are increasingly blurred such as in the rise of 'staycations' (Molz, 2009) and the focus of many cities on tourism as a regeneration strategy, leading to the ability to 'become a 
tourist in one's own city' (Binnie et al., 2007: 172). Haapala (2005) also argued that whilst strangeness does have appeal, people delight in familiar things and places precisely because of their easy familiarity which allows them to act in ways which are congruent with their own ways of being. This may in part explain the ready acceptance of leisure tourists to embrace technologies whilst on holiday so they can be virtually connected to social networks across geographical distance. Edensor (2007) also investigates this and suggests that rather than simply being about an escape from the stresses and strains of everyday life, that tourism is replete with notions of the everyday and that 'tourists carry quotidian habits and responses with them along with their luggage' (p199-200). Despite these connections to 'home', the leisure tourist does differ markedly from the business traveller by virtue of their readiness to embrace the experience of difference through bodily and sensuous encounters which are recalled as experiences to be remembered as characteristic of a particular destination.

For the business traveller, technology enables a certain disconnect from such experiences and a focus on home to engage in family life. It also enables opportunities for extended working to free up time for family life on their return. Interestingly, the business tourist gaze then can be seen to prioritise the visual (in terms of screen time) as opposed to the more embodied experiences through which tourists in other circumstances might come to know their destination. Such contact through technology can mean however, that the business traveller is immersed in a 'hybrid space of in-betweenness' (Hannam et al., 2014: 178) which can further distract the individual's attention from their physical experiences. The voices of the business travellers in this study emphasise how this state is constructed by working longer hours and undertaking chores to maximise family time at home. In this way, the destination simply becomes the setting for the meeting or conference and its distinctiveness is of little consequence and the gaze is constructed instead through the familiar and banal business setting and thoughts of home.

Importantly, although digital technologies enable this sense of 'absence presence' (Gergen, 2002), the quality of contact may be questioned. They note for example, that psychological and emotional dimensions of being absent are not always adequately dealt with through the use of technology. This again was echoed through study participants who noted a certain dissatisfaction with the quality of contact afforded by technology and its inability to replace corporeal presence. This perspective is also reflective of Strenger's work (2015) who describes the tactile and three dimensional characteristics of the body's materiality which cannot be replicated in virtual meetings and is also prominent in Urry's thoughts about the prominence of corporeal travel over other forms of imaginative and virtual travel. Although a discussion of the role and value of the body in communication is beyond the scope of this study, a review of embodiment and presence by Schultze (2010) provides a useful starting point. 
Whilst undoubtedly not all business travellers feel disconnected from their destination and reluctant to fully embrace the sensuous and bodily nature of the experience (many in our sample did avail of opportunities presented), this form of frequent contemporary mobility leads to the notion of a business tourist gaze. We have argued for the business tourist gaze as an reconfiguration of the tourist gaze in which familiarity is often sought out over the 'strange' and embodied experiences may be dismissed in favour of visual and auditory encounters with home afforded by digital technology.

\section{CONCLUSION}

The mobilities paradigm serves as a pertinent reminder that the movement of people involves the complex negotiations of social and family relationships and by paying closer attention to the 'spatialities of social life' (Sheller \& Urry, 2006: 208), a much more nuanced picture can emerge of how processes of mobility shape these relationships. The qualitative data presented in this research inspired thoughts about the tourist gaze and how this appears to differ for the business traveller, some of whom in the study were less focussed on the objects of difference in the destination and who instead gravitated towards the familiar and the familial. For this group, thoughts of home motivated behaviours and led to an intensification of working practices in order to free time for family life on their return, rather than embracing the opportunities for sensuous engagement that the destination might have engendered.

Digital technologies help to maintain and reinforce the business tourist gaze through configuring a sense of presence at home whilst being physically absent. In this way, absence and presence have become distorted as travellers seek to negotiate different ways to be virtually present in different locations whilst being physically present in others. White and White (2007) discuss how this has given rise to a 'whole new vocabulary to describe and explain this phenomenon in terms such as 'virtual presence' and 'mediated presence' (p89-90). This seems particularly manifest for business travellers who thus exist in a state of 'in-betweenness' (Hannam et al., 2014). Through the voices of contemporary business travellers, this state is revealed and this study makes a contribution to a more nuanced understanding of business travel and its impacts on social relationships and experiences of destination areas, responding to Larsen's (2008) call for more 'dynamic and contextual accounts of tourism' (p30).

This work paves the way for further research into how business travel, as a significant part of modern mobilities, mediates social relationships for different groups and what the consequences might be for relationships which are characterised by taps on a screen rather than by co-presence. Importantly, the nuances of gender differences and how these 
relationships play out for those with and without children need to be exposed. The pivotal role that technology plays in enabling and maintaining the business tourist gaze and in negotiating 'presence' and 'absence' is just starting to be understood and research must move quickly to keep pace with rapidly changing technologies. Future research should also be minded to collect evidence from a wider range of business travellers to include other kinds of mobile workers and not simply those considered as 'professional'. A more gender-balanced sample could also allow for an exploration of practice along gendered lines. The extent to which the notion of the business tourist gaze can be applied to different groups of mobile workers may also provide fertile ground for further research, along with exploring emerging technologies used for negotiating relationships at a distance.

As a final point in terms of limitations, the research presented in this paper was exploratory and thus did not take account of certain nuances in domestic arrangements. For example, whether the age of children of business travellers had a particular effect on how family relationships were negotiated and whether this had any bearing on whether individuals were more or less inclined to 'disconnect' from the destination in favour of maintaining as close links as possible with home. The stage of career of the business traveller and whether they are considered to be 'hyper-mobile' and the perceptions of the destinations travelled to may also be pertinent to these discussions as well as how different social relationships (e.g. friendships) are impacted. These areas might also be taken up by future research.

\section{References}

Adey, P. (2006) "Divided We Move": The Dromologics of Airport Security and Surveillance. In Monahan, T. (Ed.) Surveillance and Society: Technological Politics and Everyday Life. New York: Routledge.

Aguilera, A. (2008) Business travel and mobile workers. Transportation Research Part A, (42), 1109-1116.

Aguiléra, A. \& Proulhac, L. (2015) Socio-occupational and geographical determinants of the frequency of long-distance business travel in France. Journal of Transport Geography, 43, 28-35.

Bauman, Z. (2000) Liquid Modernity, Cambridge, Polity Press.

Beaverstock, J. V., Derudder, B., Faulconbridge, J. R. \& Witlox, F. (2009) International Business Travel: Some Explorations. Geografiska Annaler. Series B, Human Geography, 91,193202.

Beaverstock, J.V., and budd, L. (2013). International business travel in a digital economy. Research in Transportation Business and Management, 9, 1-4. 
Bergstrom, G. (2010) Consequences of Overnight Work Travel for Personal Social Relations: Problems, Promises, and Further Repercussions, Mobilities, 5, 369-386.

Binnie, J., Edensor, T., Holloway, J., Millington, S. \& Young, C. (2007) Mundane mobilities, banal travels. Social \& Cultural Geography, 8, 165-174.

Black, I. \& Jamieson, S. (2007) Up, Up and Fading Away: the Work and Family Life of Executive International Travellers. Policy and Practice in Health and Safety, 5, 63-78.

Boden, D., and Molotch, H. (1994). The compulsion to Proximity. In Friedland, R., and D. Boden (Eds) Nowhere: Space, Time and Modernity. p257-286. Berkeley, University of California Press.

Braun, V., and Clark, V. (2006). Using thematic analysis in Psychology. Qualitative Research in Psychology 3(2), 77-101.

Casinowsky, B. G (2013) Working Life on the Move, Domestic Life at Standstill? Work-related Travel and Responsibility for Home and Family. Gender, Work and Organization, 20, 3, 311-326.

Cohen, S.A., and Gössling, S. (2015). A darker side of hypermobility. Environment Planning A, 47(8), 1661-1679.

Coles, T. (2015) Tourism mobilities: still a current issue in tourism? Current Issues in Tourism, $18,62-67$.

Coles, T., Hall, C. M. \& Duval, D. T. (2005) Mobilizing Tourism: A Post-disciplinary Critique. Tourism Recreation Research, 30, 31-41.

Coles, T. \& Hall, M. (2006) Editorial: The geography of tourism is dead. Long live geographies of tourism and mobility. Current Issues in Tourism, 9, 289-292.

Collins, D., and Tisdell, C. (2002). Gender and differences in travel lifecycles. Journal of Travel Research 41(2), 133-43.

Cresswell, T (2010). Towards a politics of mobility. Environment and Planning D: Society and Space, 28, 17-31.

Cresswell, T. (2012). On the move: Mobility in the modern world. Routledge.

Edensor, T. (2007) Mundane mobilities, performances and spaces of tourism. Social \& Cultural Geography, 8, 199-215.

Espino, C. M., Sundstrom, S. M., Frick, H. L., Jacobs, M. \& Peters, M. (2002) International business travel: impact on families and travellers. Occup Environ Med 59, 309-322.

Faulconbridge, J. R., Beaverstock, J. V., Derudder, B. \& Witlox, F. (2008). Geographies of International Business Travel in the Professional Service Economy. In Mobility and Technology in the Workplace. Edited by D. Hislop, 87-102. Oxon: Routledge. 
Faulconbridge, J. R., Beaverstock, J. V., Derudder, B. \& Witlox, F. (2009) Corporate Ecologies of Business Travel in Professional Service Firms. Working Towards a Research Agenda. European Urban and Regional Studies, 16, 295-308.

Franklin, A. \& Crang, M. (2001) The trouble with tourism and travel theory? Tourist Studies, 1, 5-22.

Gergen, K. (2002) The Challenge of Absence Presence. IN KATZ, J. (Ed.) In Perpetual Contact: Mobile Communications, Private Talk, Public Performance. Cambridge, Cambridge University Press.

Greene, T., Buckman, J., Dandeker, C. \& Greenberg, N. (2010) How communication with families can both help and hinder service members' mental health and occupational effectiveness on deployment. Military Medicine, 175, 745-749.

Gretzel, U. \& Jamal, T. (2009) Conceptualising the Creative Tourist Class: Technology, Mobility and Tourism Experiences. Tourism Analysis, 14, 471-481.

Gustafson, P. (2006). Work-related travel, gender and family obligations. Work, Employment and Society 20(3), 513-30.

Gustafson, P. (2012) Managing business travel: Developments and dilemmas in corporate travel management. Tourism Management 33, 276-284.

Gustafson, P. (2014) Business Travel from the Traveller's Persective: Stress, Stimulation and Normalization. Mobilities, 9, 63-83.

Haapala, A. (2005) On the Aesthetics of the Everyday: Familiarity, Strangeness and the Meaning of Place. In Light, A. \& Smith, J. M. (Eds.) The Aesthetics of Everyday Life. New York, Columbia University Press.

Hall, C. M. (2005) Tourism: Rethinking the social science of mobility, Harlow, Pearson.

Hannam, K. (2008) Tourism Geographies, Tourist Studies and the Turn towards Mobilities. Geography Compass 2/1, 127-139.

Hannam, K., Butler, G. \& Paris, C. M. (2014) Developments and key issues in tourism mobilities. Annals of Tourism Research, 44, 171-185.

Haynes, P. (2010) Information and Communication Technology and International Business Travel: Mobility Allies? Mobilities, 5, 547-564.

Hislop, D., and Axtell, C. (2015). The work-related affordances of business travel: a dissaggregated analysis of journey stage and mode of transport. Work, Employment and Society. 29(6), 950-968.

Hislop, D. (2013). Driving, communicating and working: Understanding the worl realted behaviours of business travellers on work-related car journeys. Mobilities, 8(2), 220-237.

Holloway, I., Todres, L. (2003). The status of method: flexibility , consistency and coherence. Qualitative Research 3(3), 345-357. 
Ivancevich, J. M., Konopaske, R. \& DeFrank, R. S. (2003) Business travel stress: a model, propositions and managerial implications. Work and Stress, 17, 138-157.

Janta, H., Cohen, S. \& Williams, A. M. (2014) Rethinking Visiting Friends and Relatives Mobilities. Population, Space and Place, 21, 585-598.

Jones, A. (2013) Conceptualising business mobilities: Towards an analytical framework. Research in Transportation Business \& Management 9, 58-66.

Kesselring, S. \& Vogl, G. (2010) '...Travelling Where the Opponents are': Business Travel and the Social Impacts of the New Mobilities Paradigm. In Beaverstock, J.V., Derudder, B., Falconbridge, J. \& Witlox, F. (Eds.) International Business Travel in the Global Economy. Farnham, Ashgate.

Larsen, J. (2008) De-exoticizing Tourist Travel: Everyday Life and Sociality on the Move. Leisure Studies, 27, 21-34.

Larsen, J. \& Urry, J. (2011) Gazing and performing. Environment and Planning D: Society and Space 29, 1110-1125.

Larsen, J., Urry, J. \& Axhausen, K. (2006) Mobilities, Networks, Geographies, UK, Ashgate.

Lund-Durlacher, D. \& Dimanche, F. (2013) Mobilities and sustainable tourism: an introduction. Journal of Sustainable Tourism, 21, 505-510.

Lyons, G., Jain, J. and Holley, D. (2007) The use of travel time by rail passengers in Great Britain. Transportation Research Part A: Policy and Practice, 41(1),107.

Molz, J. G. (2009) Representing Pace in Tourism Mobilities: Staycations, Slow Travel and The Amazing Race. Journal of Tourism and Cultural Change, 7, 270-286.

Molz, J. G. (2012) Travel Connections. Tourism, technology and togetherness in a mobile world. Routledge, London.

Moscardo, G., Konovalov, E., Murphy, L. \& McGehee, N. (2013) Mobilities, community wellbeing and sustainable tourism. Journal of Sustainable Tourism, 21, 532-556.

ONS (2015) Travel Trends, 2014. Office for National Statistics.

Räsänen, M., Moberg, A., Picha, M., and Borggren, C. (2010). Meeting at a distance: expereinces of media companies in Sweden. Technology in Society 32, 4, 264-273.

Schultze, U. (2010). Embodiment and presence in virtual worlds: A review. Journal of Information Technology, 25(4), p434-449

Sheller, M. \& Urry, J. (2006) The new mobilities paradigm. Environment and Planning A 38, 207-226.

Strauss, A., and J. Corbin. 1998. Basics of Qualitative Research: Techniques and Procedures for Developing Grounded Theory. 2nd ed. London: Sage.

Strengers, Y. (2015). Meeting in the global workplace: Air travel, telepresence and the body. Mobilities, 10(4), 592-608. 
Swarbrooke, J. \& Horner, S. (2001) Business Travel and Tourism, Oxford, ButterworthHeinemann.

Tretyakevich, N. \& Maggi, R. (2012) Not just for business: some evidence on leisure motivations of conference attendees. Current Issues in Tourism, 15, 391-395.

UNWTO (2014) Global Report on the Meetings Industry. AM Reports, Volume 7. Madrid, UNWTO.

UNWTO (2015) Tourism Highlights 2015 Edition. Madrid, Spain.

Urry, J. (1990, 2002) The Tourist Gaze, London, Sage Publications.

Urry, J. (2002). Mobility and Proximity. Sociology 36, 255-274.

Urry, J. \& Larsen, J. (2011) The Tourist Gaze (3rd Edition), Sage, London.

Urry, J. (2012) Social networks, mobile lives and social inequalities. Journal of Transport Geography 21, p24-30.

Wajcman, J., Bittman, M. \& Brown, J. E. (2008) Families without Borders: Mobile Phones, Connectedness and Work-Home Divisions. Sociology, 42, 635-652.

Westman, M. \& Etzion, D. (2002) The impact of short overseas business trips on job stress and burnout. Applied Psychology: An International Review, 51, 582-592.

Westman, M., Etzion, D., and Chen, S. (2009). Are business trips a unique kind of respite? In Current Perspectives on Job-Stress Recovery. Edited by Sonnetag, S., Ganster, D.C., and P.L. Perrewe,. 167-204. Bingley: Emerald.

White, N. R. \& White, P. B. (2007) Home and Away. Tourists in a Connected World Annals of Tourism Research, 34, 88-104.

Williams, A. (2013) Mobilities and sustainable tourism: path-creating or path-dependent relationships? Journal of Sustainable Tourism, 21, 511-531.

Acknowledgement is given to the Economic and Physical Sciences Research Council (EPSRC) as funders of this research. Grant Reference EP/KO25619/1 
Table 1: Sample Characteristics

\begin{tabular}{|c|c|c|c|c|}
\hline $\begin{array}{l}\text { Business } \\
\text { Traveller }\end{array}$ & Gender & $\begin{array}{c}\text { Frequency } \\
\text { away }^{1}\end{array}$ & Occupation & Children \\
\hline 1 & Male & Once a month & Consultant & Yes \\
\hline 2 & Female & 3 nights weekly & Other & Yes \\
\hline 3 & Male & 2 nights weekly & Consultant & Yes \\
\hline 4 & Female & Frequent overnight & NGO & No \\
\hline 5 & Female & 10-20 trips per year & Consultant & No \\
\hline 6 & Male & 1-2 nights per week & Consultant & Yes \\
\hline 7 & Male & Frequently & $\mathrm{NGO}$ & Yes \\
\hline 8 & Male & Frequent Weekends & Training & No \\
\hline 9 & Male & 4-10 trips per month & Flight crew (pilot) & Yes \\
\hline 10 & Male & 3-4 nights per week & Tech. advisor & No \\
\hline 11 & Male & 4-10 trips per month & Journalist & Yes \\
\hline 12 & Female & $\begin{array}{c}\text { Frequent few days or } \\
\text { week away }\end{array}$ & Consultant & Yes \\
\hline 13 & Male & 3-4 trips per year & Academic & No \\
\hline 14 & Male & 10-20 trips per year & Sales Director & Yes \\
\hline 15 & Female & 1 week every 6 weeks & NGO & Yes \\
\hline 16 & Male & Once a week & Academic & Yes \\
\hline 17 & Male & 1 or 2 weeks per month & Oil industry & Yes \\
\hline 18 & Female & 1 trip per month & Law & Yes \\
\hline 19 & Male & $\begin{array}{c}\text { Several longer trips per } \\
\text { year }\end{array}$ & Publishing & Yes \\
\hline 20 & Female & $\begin{array}{c}\text { Long duration trips 6-12 } \\
\text { months }\end{array}$ & NGO & No \\
\hline 21 & Male & $\begin{array}{c}\text { Frequent away mixed } \\
\text { periods }\end{array}$ & Flight crew & No \\
\hline 22 & Male & 1 or 2 weeks per month & Oil Industry & No \\
\hline
\end{tabular}

